\title{
EFEKTIVITAS BEBERAPA MEDIA UNTUK PERBANYAKAN AGENS HAYATI Trichoderma sp.
}

\author{
Gusnawaty HS, Muhammad Taufik, La Ode Santiaji Bande, \& Agus Asis \\ Jurusan Agroteknologi Fakultas Pertanian Univeristas Halu Oleo \\ Kampus Bumi Tridharma Anduonohu JL. H.E.A. Mokodompit 93232 \\ E-mail: gusna_hs@yahoo.co.id
}

\begin{abstract}
Effectiveness of several media for propagation biological agent Trichoderma sp.. This study aims to investigate at the effectiveness of some media to propagation of Trichoderma sp. and to determine the effectiveness of the media that has the best propagation of Trichoderma sp. This research consists seven treatment propagation medium; media dregs sago, dregs of the cashew nut shell, sawdust, maize, bran, rice, and husk. The results showed that the medium used for propagation Trichoderma sp. have varying effectiveness. The most effective media for propogation Trichoderma sp. was media bran, with growth capability Trichoderma sp on 4 days after incubation (100\%), the difference in weight of the media before and after incubation Trichoderma sp. was 2,04 $\mathrm{g}$ and the number of conidia was 104,125.103/g media.
\end{abstract}

Key words: effectiveness, media, propagation, Trichoderma sp.

\section{ABSTRAK}

Efektivitas beberapa media untuk perbanyakan agens Hayati Trichoderma sp. Penelitian ini bertujuan untuk melihat efektivitas beberapa media untuk perbanyakan Trichoderma sp. dan untuk mengetahui media yang memiliki efektivitas terbaik untuk perbanyakan Trichoderma sp.Penelitian ini disusun dalam Rancangan Acak Lengkap (RAL), terdiri atas tujuh perlakuan media perbanyakan yaitu 1) Media ampas sagu (A), 2) Media ampas kulit biji mete (B), 3) Media serbuk gergaji (C), 4) Media jagung (D), 5) Media dedak (E), 6) Media beras (F), 7) Media sekam padi (G). Hasil penelitian menunjukkan bahwa media yang digunakan untuk perbanyakan Trichoderma sp. memiliki efektivitas berbeda-beda. Media yang paling efektif untuk perbanyakan Trichoderma sp. adalah media dedak, dengan kemampuan pertumbuhan Trichoderma sp. pada 4 hari setelah inkubasi mencapai $100 \%$, selisih bobot media sebelum dan sesudah inkubasi Trichoderma sp. 2,04 g dan jumlah konidia 104,125.10³/g media.

Kata kunci : efektifitas, media, perbanyakan, Trichoderma sp.

\section{PENDAHULUAN}

Trichoderma sp. merupakan cendawan saprofit tanah yang secara alami menyerang cendawan patogen dan bersifat menguntungkan bagi tanaman. Trichoderma sp. mampu memarasit cendawan patogen tanaman dan bersifat antagonis, karena memiliki kemampuan untuk mematikan atau menghambat pertumbuhan cendawan lain. Mekanisme yang terjadi di dalam tanah oleh aktivitas Trichoderma sp. yaitu (1) kompetitor ruang maupun nutrisi, (2) antibiosis yaitu mengeluarkan etanol yang bersifat racun bagi patogen dan (3) sebagai mikoparasit serta mampu menekan aktivitas cendawan patogen (Purwantisari et al., 2009).

Efektivitas Trichoderma sp. sebagai agens hayati telah banyak dilaporkan seperti hasil penelitian Sunarwati \& Yoza (2010) bahwa pemberian Trichoderma sp. sangat efektif menekan perkembangan penyakit
Phytophthora palmivora pada tanaman durian sampai mencapai 99\%. Dilaporkan juga bahwa aplikasi Trichoderma sp. pada tanaman tomat dapat menurunkan kehilangan hasil tanaman akibat infeksi penyakit layu fusarium (Taufik, 2008). Cendawan Trichoderma sp. juga mampu berperan sebagai agens biokontrol untuk mengendalikan bakteri Erwinia sp. pada Aloe vera (Mukarlina et al., 2013).

Selain kemampuan sebagai agens hayati, Trichoderma sp. juga banyak dimanfaatkan sebagai stimulator pertumbuhan tanaman seperti yang diungkapkan oleh Afitin dan Darmanti (2009) bahwa penggunaan Trichoderma sp. sebagai stimulator pada pengomposan bahan organik mampu memberikan efektivitas yang baik dalam meningkatkan produksi jagung. Menurut Tran (2010) Trichoderma sp. juga dapat berperan sebagai cendawan pengurai, pupuk hayati dan sebagai biokondisioner pada benih. 
Trichoderma sp. dapat tumbuh pada berbagai media. Media yang sering digunakan saat ini untuk perbanyakan Trichoderma sp. adalah media beras dan jagung, tetapi media tersebut untuk perbanyakaan secara massal memerlukan biaya yang lebih tinggi. Untuk itu diperlukan suatu media alternatif baru yang dapat digunakan sebagai media biakan yang memiliki nilai ekonomi rendah,cukup nutrisi, efektif, mudah didapatkan, ketersediaan bahan baku berlimpah dan dapat dimanfaatkan oleh Trichoderma sp. untuk tumbuh dan berkembang. Oleh karena itu penelitian ini bertujuan untuk menguji efektivitas beberapa media sebagai bahan/ media perbanyakan Trichoderma sp. untuk mengevaluasi media yang memiliki efektivitas terbaik untuk perbanyakan Trichoderma sp.

\section{METODE PENELITIAN}

Tempat dan Waktu. Penelitian ini dilaksanakan di Laboratorium Jurusan Agroteknologi Unit Ilmu Hama dan Penyakit Tumbuhan, Fakultas Pertanian Universitas Halu Oleo, yang dilaksanakan pada Bulan Januari 2013.

Bahan yang digunakan adalah biakan murni cendawan Trichoderma sp., aquades, agar-agar, alkohol $70 \%$, media PDA (Potato Dextrosa Agar), ampas sagu, ampas kulit biji mete, serbuk gergaji, jagung, dedak dan beras. Penelitian ini disusun berdasarkan Rancangan Acak Lengkap (RAL) dengan 7 (tujuh) perlakuan media perbanyakan Trichoderma sp. yaitu: 1) Media ampas sagu (A), 2) Media ampaskulit biji mete (B), 3) Media serbuk gergaji (C), 4) Media Jagung (D), 5) Media dedak (E), 6) Media beras (F), 7) Media sekam padi (G). Masing-masing perlakuan diulang sebanyak 4 kali sehingga terdapat 28 unit percobaan.

Inokulum cendawan Trichoderma sp. adalah koleksi Laboratorium IHPT Fakultas Pertanian Universitas Halu Oleo yang kemudian disegarkan kembali pada media Potato Dextrosa Agar (PDA). Pembuatan media jagung dan beras dilakukan dengan cara masing-masing media direndam selama 24 jam setelah itu dicuci dan dikukus sampai lunak. Untuk media dedak, sekam padi, limbah jambu mete dan serbuk gergaji direndam selama 24 jam kemudian diperas sampai kandungan air media dalam kondisi kapasitas lapang sedangkan media ampas sagu cukup dikeringanginkan. Selanjutnya masing-masing media ditimbang sebanyak $30 \mathrm{~g}$ dan dimasukkan ke dalam botol, kemudian ditutup dengan aluminium foil. Selanjutnya botol berisi media disterilkan dalam autoklaf pada suhu $121^{\circ} \mathrm{C}$ selama 15 menit dan siap untuk digunakan sebagai media perbanyakan. Pada masing-masing media selanjutnya diinokulasikan cendawan Trichoderma sp. yang telah ditumbuhkan pada media PDA selama tigaminggu setelah inkubasi (MSI), sebanyak 1 (satu) koloni dengan ukuran diameter yaitu $5 \mathrm{~mm}$, selanjutnya diinkubasi dan siap untuk dilakukan pengamatan.

Pengamatan dilakukan sejak inokulasi Trichoderma sp. pada setiap media dilakukan sampai media tersebut ditumbuhi dan dipenuhi oleh Trichoderma sp. Beberapa variabel yang diamati pada penelitian ini yaitu: Periode inkubasi Trichoderma sp., persentase pertumbuhan Trichoderma sp. selisih berat media sebelum dan setelah inokulasi Trichoderma sp., dan jumlah spora/konidia yang dihasilkan Trichoderma sp. pada setiap media perbanyakan.

Periode inkubasi Trichoderma sp. yaitu waktu yang diperlukan Trichoderma sp. untuk memperbanyak diri pada setiap media (waktu sejak inokulasi Trichoderma sp. pada media sampai Trichoderma sp. mulai memperbanyak diri). Persentase pertumbuhan Trichoderma sp. pada media perbanyakan berdasarkan persentase luas daerah media yang ditumbuhi Trichoderma sp. dilihat secara visual. Selisih berat media sebelum dan setelah inokulasi Trichoderma sp. dihitung berdasarkan berat media sebelum inokulasi Trichoderma sp. dikurangi berat media setelah Trichoderma sp. memperbanyak diri. Jumlah spora/ konidia yang dihasilkan Trichoderma sp. pada setiap media perbanyakan. Jumlah konidia dihitung menggunakan haemocytometer, dengan rumus :

$$
\mathrm{K}=\frac{\mathrm{t} \times \mathrm{d}}{\mathrm{n} \times 0,25} \times 10^{6}
$$

dengan:

$\mathrm{K}=$ Jumlah spora $/ \mathrm{ml}$ pelarut

$\mathrm{t}=$ Jumlah spora dalam semua kotak contoh

$\mathrm{d}=$ Faktor pengenceran

$\mathrm{n}=$ Jumlah semua kotak contoh yang dihitung $0,25=$ Faktor koreksi

Data yang dihasilkan dianalisis sidik ragam (uji F). Apabila diantara perlakuan bepengaruh nyata, maka dilanjutkan dengan BNJ pada taraf kepercayaan $95 \%$.

\section{HASIL DAN PEMBAHASAN}

Berdasarkan hasil pengamatan terlihat bahwa pada media yang digunakan untuk perbanyakan Trichoderma sp. memiliki efektivitas yang berbeda-beda berdasarkan persentase pertumbuhan Trichoderma sp., selisih berat sebelum dan setelah inkubasiTrichoderma $\mathrm{sp}$., dan jumlah konidia yang dihasilkan kecuali rata-rata periode inkubasi. 
Periode Inkubasi Trichoderma sp.. Berdasarkan hasil pengamatan dan analisis data terlihat bahwa untuk periode inkubasi Trichoderma sp. pada setiap media perbanyakan tidak menunjukkan perbedaan. Rata-rata periode inkubasi Trichoderma sp. pada setiap media perbanyakan yang diujikan adalah 2 (dua) hari. Hal ini menunjukkan bahwa Trichoderma sp. memiliki kemampuan untuk tumbuh pada media-media perbanyakan dalam waktu yang sama (Tabel 1).

Pada pengamatan periode inkubasi menunjukkan bahwa periode inkubasi Trichoderma sp. pada media perbanyakan yang digunakan adalah sama, yaitu ratarata 2 hari setelah inkubasi (HSI). Hal ini membuktikan bahwa Trichoderma sp. dapat tumbuh pada mediamedia perbanyakan yang digunakan. Menurut Prabowo et al. (2006) bahwa Trichoderma sp. termasuk cendawan yang mudah tumbuh pada berbagai habitat dan lingkungan. Menurut Harsono et al. (2001) bahwa Trichoderma sp. dapat menghasilkan enzim selulase sehingga mampu mendegradasi media yang mengandung selulosa. Oleh karena itu, bahwa Trichoderma sp. dapat berperan sebagai biodekomposer karena mampu memanfaatkan bahan-bahan organik terutama yang mengandung selulosa sebagai sumber karbon dan energi untuk kebutuhan hidupnya (Widyastuti et al., 2001).

\section{Persentase Pertumbuhan Trichoderma sp..} Berdasarkan Tabel 2 menunjukan bahwa pertumbuhan Trichoderma sp. pada setiap media perbanyakan pada setiap waktu pengamatan berbeda-beda (Gambar 1). Persentase pertumbuhan Trichoderma sp. tertinggi terdapat pada perlakuan media media dedak dan jagung yang berbeda nyata dengan perlakuan lainnya pada 4 hari setelah inokulasi (HSI). Pada 5 HSI terlihat pertumbuhan Trichoderma sp. pada media dedak, media jagung, media ampas sagu, media serbuk gergaji dan sekam padi tidak berbeda nyata, tetapi berbeda nyata pada media beras dan media ampas kulit biji mete. Pada 6\&7 HSI, pertumbuhan Trichoderma sp. pada media perbanyakan tidak memperlihatkan perbedaan yang nyata kecuali pada media ampas kulit biji mete.

Berbeda halnya pada pengamatan persentase pertumbuhan Trichoderma sp. pada setiap media perbanyakan adalah berbeda-beda. Pada media dedak dan jagung, pada 4 HSI, pertumbuhan Trichoderma sp. sudah mencapai $100 \%$. Hal ini dimungkinkan karena

Tabel 1. Rata-rata periode inkubasi Trichoderma sp. pada berbagai media perbanyakan (hari)

\begin{tabular}{lc}
\hline \multicolumn{1}{c}{ Perlakuan } & Rata-rata periode inkubasi (hari) \\
\hline Media ampas sagu (A) & 2 \\
Media ampas kulit biji mete (B) & 2 \\
Media serbukgergaji (C) & 2 \\
Media jagung (D) & 2 \\
Media dedak (E) & 2 \\
Media beras (F) & 2 \\
Media sekampadi (G) & 2 \\
\hline
\end{tabular}

Tabel 2. Persentase pertumbuhan Trichoderma sp. pada berbagai media perbanyakan pada berbagai waktu pengamatan $(\%)$

\begin{tabular}{lcccccc}
\hline & \multicolumn{7}{c}{ Hari setelah inkubasi (HSI) $\%$} \\
\cline { 2 - 7 } \multicolumn{1}{c}{ Perlakuan } & 2 & 3 & 4 & 5 & 6 & 7 \\
\hline Media ampas sagu (A) & $25 \mathrm{a}$ & $76,25 \mathrm{ab}$ & $93,75 \mathrm{ab}$ & $100 \mathrm{a}$ & $100 \mathrm{a}$ & $100 \mathrm{a}$ \\
Media ampas kulit biji mete (B) & $5 \mathrm{c}$ & $10,00 \mathrm{~d}$ & $15,00 \mathrm{~d}$ & $37,5 \mathrm{c}$ & $47,5 \mathrm{~b}$ & $60 \mathrm{~b}$ \\
Media serbuk gergaji (C) & $6,25 \mathrm{c}$ & $43,75 \mathrm{c}$ & $76,25 \mathrm{~b}$ & $100 \mathrm{a}$ & $100 \mathrm{a}$ & $100 \mathrm{a}$ \\
Media jagung (D) & $25 \mathrm{a}$ & $50,00 \mathrm{bc}$ & $100 \mathrm{a}$ & $100 \mathrm{a}$ & $100 \mathrm{a}$ & $100 \mathrm{a}$ \\
Media dedak (E) & $10 \mathrm{~b}$ & $87,50 \mathrm{a}$ & $100 \mathrm{a}$ & $100 \mathrm{a}$ & $100 \mathrm{a}$ & $100 \mathrm{a}$ \\
Media beras (F) & $5 \mathrm{c}$ & $10,00 \mathrm{f}$ & $43,75 \mathrm{c}$ & $71,25 \mathrm{~b}$ & $95 \mathrm{a}$ & $100 \mathrm{a}$ \\
Media sekam padi (G) & $25 \mathrm{a}$ & $50,00 \mathrm{bc}$ & $75,00 \mathrm{~b}$ & $100 \mathrm{a}$ & $100 \mathrm{a}$ & $100 \mathrm{a}$ \\
\hline
\end{tabular}

Angka yang diikuti huruf berbeda pada kolom yang sama menunjukkan perbedaan nyata menurut uji BNJ $\alpha 0,05$ 
kandungan nutirisi pada media dedak dan jagung yang lebih banyak dan kompleks untuk kebutuhan Trichoderma sp. Selain itu Trichoderma sp. mampu menghasilkan enzim selulase yang dapat mendagradasi selulosa sehingga mempercepat asupan nutrisi bagi pertumbuhan cendawan dan mempercepat ketersediaan hara. Hal ini juga dikemukan oleh Ratanaphadit et al. (2010) bahwa kemampuan cendawan Trichoderma sp. untuk memproduksi enzim seperti enzim selulotik yaitu endoglukanase dan ektoglukanase sehingga mampu berperan dalam menghidrolisis selulosa.Pada media limbah sagu, serbuk gergaji, sekam padi dan beras menunjukan kemampuan tumbuh $100 \%$ pada 5 \& 6 HSI. Persentase pertumbuhan terendah terdapat pada media ampas kulit mete dimana sampai pada 7 HSI hanya mampu menunjukkan kemampuan tumbuh $60 \%$. Pertumbuhan Trichoderma sp. pada media ampas kulit biji mete lebih lambat dari media lainnya diduga karena kandungan nutrisi media yang rendah dan kemungkinan masih terdapatnya sisa-sisa Cashew Nut Shell Liquid (CNSL)yang bersifat menghambat pertumbuhan cendawan sehingga kemampuan tumbuh Trichoderma sp. menjadi lebih rendah.

\section{Selisih Bobot Media Sebelum dan Setelah} Inokulasi/Iknubasi Trichoderma sp.. Berdasarkan hasil pengamatan (Tabel 3) terlihat bahwa ada selisih bobot yang terjadi antara bobot awal media sebelum inokulasi dengan bobot media setelah inkubasi Trichoderma sp. pada setiap media perbanyakan. Selisih tersebut menunjukkan adanya pengurangan bobot media setelah inokulasi Trichoderma sp.. Penurunan bobot media tertinggi terdapat pada media dedak yaitu $2,04 \mathrm{~g}$, sedangkan penurunan bobot terendah terdapat pada media ampas kulit biji mete yaitu $0,8 \mathrm{~g}$.
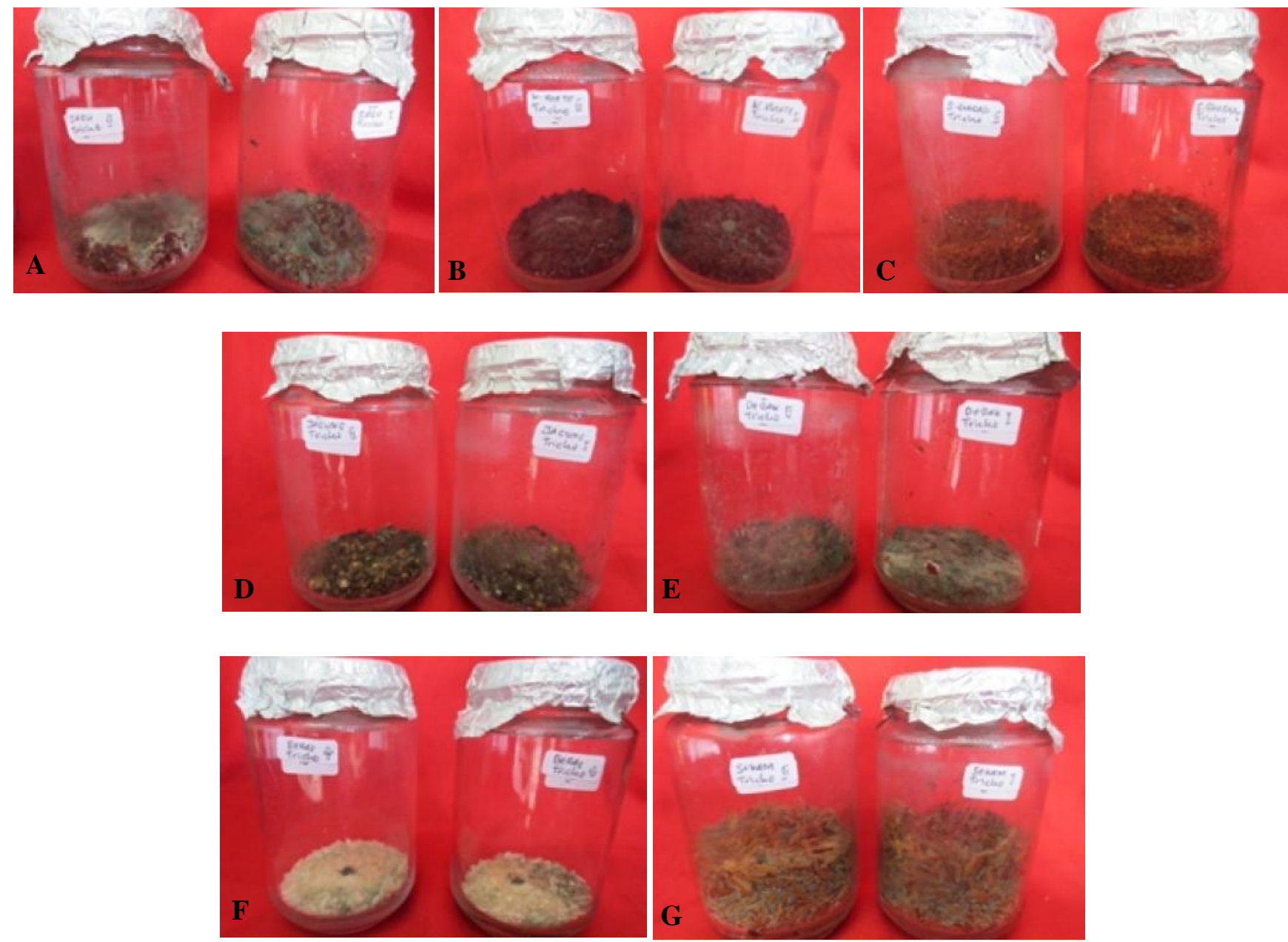

Gambar 1. Pertumbuhan Trichoderma sp. pada setiap media perbanyakan pada 7 HSI; (A) Media ampas kulit biji mete; (B) Media serbuk gergaji; (C) Media jagung; (D) Media dedak; (E) Media beras; (F) Media sekam padi 
Pada pengamatan selisih bobot media perbanyakan sebelum dan sesudah inkubasi Trichoderma sp. terlihat bahwa media yang memiliki selisih bobot tertinggi adalah media dedak yaitu $2,04 \mathrm{~g}$ yang berbeda nyata dengan bobot pada media beras, media jagung, media limbah sekam padi, media limbah serbuk gergaji, media ampas kulit mete dan media sagu. Hal ini diduga karena Trichoderma sp. memiliki kemampuan untuk merombak dedak yang lebih cepat dibandingkan dengan media lainnya karena kesesuaian nutrisi yang dibutuhkan dengan nutrisi yang tersedia pada media.

Pengurangan bobot media setelah inkubasi Trichoderma sp. pada media terjadi karena menurut: (1) Hilakore (2008) bahwa kemampuan cendawan memanfaatkan bahan media biakan tidak dapat meningkatkan bobot secara signifikan, tetapi dapat meningkatkan serat kasar yang dihasilkan dari miselium cendawan, (2) Syahrir \& Abdeli (2005) bahwa adanya aktifitas cendawan juga menyebabkan berkurangnya kadar air akibat termanfaatkan dalam mendekomposer media perbanyakan sebagai sumber makanan bagi cendawan. Oleh karena itu, pengurangan bobot yang terjadi pada media perbanyakan merupakan hal yang semestinya dan menunjukkan adanya aktivitas dari cendawan pada media tersebut. Dengan demikian semakin besar selisih bobot media sebelum dan sesudah inkubasi Trichoderma sp. berarti semakin tinggi aktivitas Trichoderma sp. sebagai pengurai/dekomposer pada media.

Jumlah Konidia Trichoderma sp.. Berdasarkan hasil pengamatan pada Tabel 4 terlihat bahwa pada rata-rata jumlah konidia cendawan Trichoderma sp. tertinggi adalah media dedak $1,04 \times 10^{5} / \mathrm{g}$ media yang berbeda nyata dengan perlakuan lainnya. Pada media ampas sagu, beras, jagung dan sekam padi tidak berbeda nyata, tetepi berbeda nyata pada media serbuk gergaji dan ampas kulit biji mete. Pada media ampas kulit jambu mete nampaknya tidak mendukung pertumbuhan konidia, karena pada media tersebut jumlah konidia yang dihasilkan hanya mencapai $6 \times 10^{3} / \mathrm{g}$ media. Media

Tabel 3. Rata-rata selisih bobot media sebelum dan setelah inkubasi masing-masing media perbanyakan Trichoderma sp.

\begin{tabular}{lccc}
\hline \multicolumn{1}{c}{ Perlakuan } & $\begin{array}{c}\text { Bobot sebelum } \\
\text { inkubasi }(\mathrm{g})\end{array}$ & $\begin{array}{c}\text { Bobot setelah } \\
\text { inkubasi }(\mathrm{g})\end{array}$ & $\begin{array}{c}\text { Selisih Bobot } \\
(\mathrm{g})\end{array}$ \\
\hline Media ampas sagu (A) & 246,52 & 245,21 & $1,30 \mathrm{~b}$ \\
Media ampas kulit biji mete (B) & 249,70 & 248,90 & $0,80 \mathrm{~b}$ \\
Media serbukgergaji (C) & 242,26 & 241,41 & $0,85 \mathrm{~b}$ \\
Media jagung (D) & 252,43 & 251,30 & $1,14 \mathrm{~b}$ \\
Media dedak (E) & 241,10 & 239,06 & $2,04 \mathrm{a}$ \\
Media beras (F) & 248,84 & 247,85 & $0,99 \mathrm{~b}$ \\
Media sekam padi (G) & 227,48 & 226,56 & $0,92 \mathrm{~b}$ \\
\hline
\end{tabular}

Angka yang diikuti huruf berbeda pada kolom yang sama menunjukkan perbedaan nyata menurut uji BNJ $\alpha 0,05$

Tabel 4. Rata-rata jumlah konidiaTrichoderma sp. pada berbagai media perbanyakan (per gram media)

\begin{tabular}{lc}
\hline \multicolumn{1}{c}{ Perlakuan } & $\begin{array}{c}\text { Rata-rata jumlah konidia cendawan Trichoderma sp. pada media } \\
\text { perbanyakan }\left(10^{3} / \mathrm{g} \text { media }\right)\end{array}$ \\
\hline Media ampas sagu (A) & $28,625 \mathrm{bc}$ \\
Media ampas kulit biji mete (B) & $6,00 \mathrm{~d}$ \\
Media serbukgergaji (C) & $3,125 \mathrm{~d}$ \\
Media jagung (D) & $45,25 \mathrm{ab}$ \\
Media dedak (E) & $104,125 \mathrm{a}$ \\
Media beras (F) & $17,125 \mathrm{c}$ \\
Media sekam padi (G) & $21,375 \mathrm{bc}$ \\
\hline
\end{tabular}

Angka yang diikuti huruf berbeda pada kolom yang sama menunjukkan perbedaan nyata menurut uji BNJ $\alpha 0,05$ 
tersebut menjadi perlakuan dengan jumlah konidia Trichoderma sp. yang dihasilkan paling rendah dan berbeda nyata dengan perlakuan media lainnya.

Pada hasil pengamatan jumlah konidia Trichoderma sp. yang terbentuk pada setiap media terlihat bahwa jumlah konidia Trichoderma sp. terbanyak terdapat pada media dedak dengan jumlah konidia $104,125.10^{3} / \mathrm{g}$ media yang berbeda nyata dengan media lainnya. Pada media sagu dan sekam padi jumlah konidia tidak berbeda nyata, tetapi berbeda nyata dengan perlakuan beras, ampas kulit mete, jagung dan serbuk gergaji.

Dengan demikian, dalam perbanyakan Trichoderma sp. jika ditujukan untuk menghasilkan jumlah konidia Trichoderma sp. yang lebih banyak maka media beras dapat digantikan dengan media dedak yang nilai ekonominya lebih murah tetapi mampu mendukung terbentuknya konidia Trichoderma sp. yang sama jika menggunakan media beras. Perbedaan jumlah konidia Trichoderma sp. yang terbentuk dimungkinkan erat kaitannya dengan kandungan nutrisi dari setiap media. Tinggi rendahnya jumlah konidia pada setiap media diduga sangat dipengaruhi oleh ketersediaan selulosa pada media sebagai sumber makanan. Hal ini diungkapkan juga oleh Armaini et al. (1995) bahwa cendawan Trichoderma sp. yang tumbuh pada media yang mengandung selulosa mampu menghasilkan banyak enzim selulase dan media yang mengandung sukrosa dan glukosa dengan jumlah yang sedikit menghasilkan enzim selulase dengan jumlah yang sedikit pula sehingga aktifitas cendawan tidak begitu terlihat.

Oleh karena itu, berdasarkan hasil penelitian ini secara umum dapat dikatakan bahwa media dedak adalah media yang paling efektif untuk digunakan sebagai media perbanyakan Trichoderma sp. karena pada setiap variabel pengamatan menunjukan kemampuan Trichoderma sp. untuk tumbuh dan berkembang yang lebih baik dibandingkan pada media tumbuh lainnya, sehingga media beras dan jagung yang umumnya digunakan untuk perbanyakan Trichoderma sp. dapat digantikan dengan media dedak yang nilai ekonominya lebih murah dan terjangkau dan hasilnya sama jika menggunakan media beras dan jagung.

\section{SIMPULAN}

Berdasarkan hasil penelitian ini maka dapat disimpulkan bahwa media yang digunakan untuk perbanyakan Trichoderma sp. memiliki efektifitas berbeda-beda dan media yang paling efektif untuk perbanyakan Trichoderma sp. adalah media dedak, dengan kemampuan pertumbuhan Trichoderma sp. 100
$\%$ pada hari ke-4 HSI, selisih bobot media sebelum dan setelah inokulasi/inkubasi 2,04 g dan jumlah konidia $104,125.10^{3} / \mathrm{g}$ media.

\section{DAFTAR PUSTAKA}

Afitin R \& Darmanti S. 2009. Pengaruh dosis kompos dengan stimulator Trichoderma sp. terhadap pertumbuhan dan produksi tanaman jagung (Zea mays L.) varietas pioner pada lahan kering. $J$. Bioma. 11(2): 69-75.

Armaini, Mardiah E, \& Dharma A. 1995. Pengaruh karbohirat terhadap media fermentasi untuk memproduksi enzim selulase dari Trichoderma sp. Lembaga Penelitian Universitas Andalas. Andalas.

Chandel AK, Chan ES, Rudraavaram R, Narasu ML, Rao LV, \& Ravindra P. 2007. Economic and enviromental impact of bioethanol production Technologies : An Appraisal. Biotechnology and Molecular Biology Review. 2(1): 14-32.

Gerhatz W. 1990. Enzym in Industry Production and Application. VCH Verlagsgesellschaft mbH, D. 6940 Weinheim.

Hilakore MA. 2008. Peningkatan kualitas nutritif putak melalui fermentasi campuran Trichoderma reesei dan Aspergillus niger sebagai pakan ruminansia. Tesis. Sekolah Pascasarjana. Institut Pertanian Bogor.

Mukarlina, Khotimah S, \& Febrianti L. 2013. Uji antagonis Trichoderma harzianum terhadap Erwinia sp. penyebab penyakit busuk bakteri pada Aloe vera. J. Fitomedika 7(3): 150-154.

Prabowo AKE, Prihatiningsih N, \& Soesanto L. 2006. Potensi Trichoderma harzianum dalam mengendalikan sembilan isolat Fusarium oxysporum Schelecht.f.sp.zingiberi trijillo pada kencur. J. Ilmu-Ilmu Pertanian Indonesia. 8(2): 76-84.

Purwantisari S \& Hastuti RB. 2009. Uji antagonisme jamur Phytophthora infestans penyebab penyakit busuk daun dan umbi kentang dengan menggunakan Trichoderma spp. isolat lokal. $J$. Bioma. 11(1): 24-32.

Ratanaphadit K, Kaewjan K, \& Palakas S. 2010. Potential of glycoamylase and cellulase production using mixed culture of Aspergillusniger TISTR 3254 and Trichodermareesei TISTR 3081. KKU Res J. 15(9): 833-842. 
Sunarwati D \& Yoza R. 2010. Kemampuan Trichoderma sp dan Penicillium dalam menghambat pertumbuhan cendawan penyebab penyakit busuk akar durian (Phytoptora palmivora) secara in-vitro. Prosiding. Seminar Nasional Program dan Strategi Pengembangan Buah Nusantara. Balai Penelitian Tanaman Buah. Solok.

Syahrir \& Abdeli M. 2005. Analisis kandungan zat-zat makanan kulit buah kakao yang difermentasi dengan Trichoderma sp. sebagai akan ternak ruminansia. J. Agrisains. 6(3): 157-165.
Taufik M. 2008. Efektivitas agen antagonis Trichoderma sp. pada berbagai media tumbuh terhadap penyakit layu tanaman tomat. Prosiding. Seminar Ilmiah dan Pertemuan Tahunan PEI PFI XIX Komisariat Sulawesi Selatan. Makassar.

Tran N.Ha. 2010. Using Trichoderma species for biological control of plant pathogens in Vietnam. J. ISSAAS. 1(16):17-21.

Widyastuti SM, Sumardi, \& Sumantoro P. 2001. Efektifitas Trichoderma spp. sebagai pengendali hayati terhadap tiga patogen tular tanah pada beberapa jenis tanaman kehutanan. $J$. Perlindungan Tanaman Indonesia. 7(2): 98107. 